\title{
Hubungan Indeks Kepuasan Pasien tentang Mutu Pelayanan Dimensi Kehandalan dengan Minat Berobat Kembali di RSD Kalisat Kabupaten Jember
}

\section{(Correlation between Patient Satisfaction Index in Reliability of Service Quality and Utility at RSD Kalisat Jember)}

\author{
Davina Amalia, Dwita Aryadina Rachmawati, Hairrudin \\ Fakultas Kedokteran Universitas Jember \\ Jln. Kalimantan 37, Jember 68121 \\ e-mail:dr.dwita@gmail.com
}

\begin{abstract}
$R S D$ Kalisat is one of the hospital that is very concern with the quality of health services. The reliability of service quality is often perceived as the most important dimension for the customer. Quality of service is very influential on patient satisfaction. If the health care provided is good, then the patient will be satisfied and the possibility to reuse services in health care-related agencies will increase. The purpose of this study was to determine the correlation between patient satisfaction index in the reliability of service quality with utility at RSD Kalisat. This study used cross sectional design with total sample of 84 respondents. The instrument used was RSD Kalisat profile and questionnaire to determine patient satisfaction index in the reliability of service quality and statement for utility. The results of statistical test by Spearman's Rho showed a significance value $(p=0.021)$ and the correlation coefficient $(r$ $=0.252$ ). Thus, it can be concluded that there was a significant correlation between patient satisfaction index in the reliability of service quality with utility at RSD Kalisat Jember with a weak correlation.
\end{abstract}

Keywords: index satisfaction, reliability, service quality, utility

\begin{abstract}
Abstrak
RSD Kalisat merupakan salah satu rumah sakit yang sangat mementingkan mutu pelayanan kesehatan. Dimensi kehandalan mutu pelayanan sering dipersepsikan menjadi yang paling penting bagi pelanggan dari bagian industri jasa. Mutu pelayanan sangat berpengaruh pada kepuasan pasien, jika pelayanan kesehatan yang diberikan baik, maka pasien akan merasa puas dan kemungkinan untuk menggunakan kembali jasa di instansi pelayanan kesehatan yang terkait lebih besar. Tujuan dari penelitian ini adalah mengetahui hubungan indeks kepuasan pasien tentang mutu pelayanan dimensi kehandalan dengan minat berobat kembali di RSD Kalisat. Penelitian ini menggunakan desain cross sectional dengan jumlah sampel sebanyak 84 responden. Instrumen yang digunakan adalah profil RSD Kalisat dan kuesioner untuk mengetahui indeks kepuasan pasien tentang mutu pelayanan dimensi kehandalan dan pernyataan minat berobat kembali. Hasil uji statistik dengan uji korelasi Spearman's Rho menunjukkan nilai signifikansi $(p=0,021)$ dan koefisien korelasi $(r=0,252)$. Dapat disimpulkan bahwa terdapat hubungan yang bermakna antara indeks kepuasan pasien tentang mutu pelayanan dimensi kehandalan dengan minat berobat kembali di RSD Kalisat Kabupaten Jember dengan korelasi yang lemah.
\end{abstract}

Kata Kunci: Indeks kepuasan, Dimensi Kehandalan, Mutu Pelayanan, Minat Berobat Kembali 


\section{Pendahuluan}

Rumah sakit merupakan salah satu fasilitas kesehatan yang banyak dimanfaatkan masyarakat. Peningkatan jumlah rumah sakit dalam tiga tahun akhir di provinsi Jawa Timur menandakan terjadi peningkatan kebutuhan pelayanan kesehatan masyarakat [1].

RSD Kalisat Kabupaten Jember merupakan rumah sakit publik dengan tipe $C$ yang memberikan pelayanan rawat jalan, rawat inap, gawat darurat, instalasi bedah dan pelayanan penunjang. Instalasi rawat jalan RSD Kalisat Kabupaten Jember terdiri atas poliklinik anak, penyakit dalam, kebidanan \& penyakit kandungan, syaraf, bedah, gigi \& mulut, dan poliklinik jantung. Berdasarkan profil RSD Kalisat Kabupaten Jember diperoleh data kunjungan di poli rawat jalan pada tahun 2013 sampai 2015 mengalami penurunan. Penurunan jumlah kunjungan pasien lama yang terjadi di RSD Kalisat Kabupaten Jember menunjukkan bahwa minat kunjungan pasien untuk melakukan pelayanan rumah sakit juga menurun.

Salah satu cara meningkatkan minat kunjungan pasien adalah melalui peningkatan pelayanan kesehatan. Pelayanan kesehatan berkaitan erat dengan mutu pelayanan kesehatan. Dimensi kehandalan merupakan salah satu dimensi dalam service quality yang dipersepsikan menjadi yang paling penting bagi pelanggan dari bagian industri jasa. Karena apabila pasien merasakan bahwa kehandalan suatu rumah sakit sangat sesuai dengan harapan, maka mereka akan bersedia mengeluarkan biaya tambahan agar rumah sakit melaksanakan transaksi seperti yang dijanjikan [2]. Kehandalan terdiri atas kemampuan pemberi layanan untuk memberikan pelayanan yang diharapkan secara akurat sesuai dengan yang dijanjikan oleh instansi kesehatan [3]. Penilaian mutu pelayanan bisa didapatkan dengan penilaian terhadap outcome. Outcome adalah evaluasi hasil akhir dari kesehatan atau kepuasan pasien. Kepuasan pasien diukur menggunakan survei kepuasan pelanggaan, yaitu directly reported satisfaction yang menanyakan secara langsung atribut pertanyaan yang diteliti [4].

Kepuasan dan ketidakpuasan terhadap pelayanan kesehatan akan mempengaruhi perilaku pasien selanjutnya. Jika pasien puas, ia akan menunjukkan kemungkinan yang lebih tinggi untuk menggunakan kembali pelayanan kesehatan di instansi kesehatan tersebut. Begitu sebaliknya jika pasien merasa tidak puas atau bahkan dirugikan maka akan berhenti menggunakan pelayanan kesehatan dan menceritakan pengalaman buruknya kepada rekan-rekannya [5].

Tujuan penelitian ini adalah untuk mengetahui hubungan antara indeks kepuasan pasien tentang mutu pelayanan dimensi kehandalan dengan minat berobat kembali di RSD Kalisat Kabupaten Jember.

\section{Metode Penelitian}

Jenis penelitian ini adalah penelitian survei analitik dengan desain cross sectional. Penelitian ini dilakukan di Poli Rawat Jalan RSD Kalisat Kabupaten Jember pada bulan Desember 2015. Populasi dalam penelitian ini adalah semua pasien di Poli Rawat Jalan, kecuali pasien di Poli Anak, dengan teknik pengambilan sampel menggunakan cluster random sampling, besar sampel yang diperlukan sebanyak 84 responden.

Kriteria inklusi dalam penelitian ini yaitu pasien yang melakukan pemeriksaan di RSD Kalisat Kabupaten Jember pada tahun 2015, pasien merupakan pasien rawat jalan, berusia $>18$ tahun dan bersedia menjadi responden dan mengikuti prosedur penelitian sampai tahap akhir. Sedangkan kriteria eksklusi penelitian ini adalah pasien yang tidak sadar atau dalam kondisi lemah sehingga tidak mampu menjadi subyek penelitian. Penelitian ini sudah mendapat Ethical Clearance dari Komisi Etik Fakultas Kedokteran Universitas Jember.

Instrumen yang digunakan dalam penelitian ini adalah profil RSD Kalisat Kabupaten Jember dan kuesioner yang digunakan untuk mengukur indeks kepuasan pasien tentang mutu pelayanan dimensi kehandalan (Tabel 1).

Tabel 1. Skala Indeks Kepuasan Pasien

\begin{tabular}{ccl}
\hline Skala & Presentse skor $(\%)$ & \multicolumn{1}{c}{ Kriteria } \\
\hline 1 & $20-35,9$ & Sangat tidak puas \\
2 & $36-51,9$ & Tidak puas \\
3 & $52-67,9$ & Netral \\
4 & $68-83,9$ & Puas \\
$\mathbf{5}$ & $84-100$ & Sangat Puas \\
\hline
\end{tabular}

Uji statistik yang digunakan adalah uji normalitas Kolmogorov-Smirnov dan uji korelasi Spearman's Rho karena jenis data dari kedua variabel yang dinilai adalah ordinal-nominal.

\section{Hasil Penelitian}

Berdasarkan data yang terkumpul, dapat diketahui tabulasi silang distribusi 
karakteristik responden dengan indeks kepuasan tentang mutu pelayanan dimensi kehandalan pada Tabel 2 di bawah ini.

Tabel 2. Tabulasi Silang Distribusi Karakteristik Responden dengan Indeks Kepuasan tentang Mutu Pelayanan Dimensi Kehandalan

\begin{tabular}{|c|c|c|c|c|}
\hline \multirow[t]{2}{*}{ Karakteristik } & \multicolumn{3}{|c|}{ Indeks Kepuasan } & \multirow[t]{2}{*}{ Total } \\
\hline & $\overline{\text { Netral }}$ & Puas & $\begin{array}{l}\text { Sangat } \\
\text { Puas }\end{array}$ & \\
\hline a. Jenis Kelamin & $\mathrm{N}$ & $\mathrm{N}$ & $\mathrm{N}$ & $\mathrm{N}$ \\
\hline $\begin{array}{l}\text { Laki-laki } \\
\text { Perempuan } \\
\text { b.Usia }\end{array}$ & $\begin{array}{l}0 \\
4\end{array}$ & $\begin{array}{l}7 \\
15\end{array}$ & $\begin{array}{l}23 \\
35\end{array}$ & $\begin{array}{l}30 \\
54\end{array}$ \\
\hline $\begin{array}{l}18-40 \\
41-60 \\
>60 \\
\text { c. Pendidikan }\end{array}$ & $\begin{array}{l}3 \\
1 \\
0\end{array}$ & $\begin{array}{l}11 \\
7 \\
4\end{array}$ & $\begin{array}{l}24 \\
23 \\
11\end{array}$ & $\begin{array}{l}38 \\
31 \\
15\end{array}$ \\
\hline Pendidikan rendah & 2 & 15 & 31 & 48 \\
\hline $\begin{array}{l}\text { Pendidikan } \\
\text { menengah }\end{array}$ & 1 & 2 & 13 & 16 \\
\hline $\begin{array}{l}\text { Pendidikan tinggi } \\
\text { d. Pekerjaan }\end{array}$ & 1 & 5 & 14 & 20 \\
\hline Wiraswasta & 0 & 5 & 8 & 13 \\
\hline Pegawai swasta & 1 & 2 & 3 & 6 \\
\hline Pegawai negeri sipil & 1 & 1 & 6 & 8 \\
\hline Petani & 1 & 4 & 9 & 14 \\
\hline Ibu rumah tangga & 1 & 6 & 17 & 24 \\
\hline Lain-lain & 0 & 4 & 15 & 19 \\
\hline \multicolumn{5}{|c|}{ e. Penghasilan Setiap Bulan } \\
\hline$<1.000 .000$ & 2 & 11 & 20 & 33 \\
\hline $\begin{array}{l}1.000 .000- \\
2.000 .000\end{array}$ & 1 & 4 & 19 & 24 \\
\hline $\begin{array}{l}2.000 .000- \\
3.000 .000\end{array}$ & 1 & 3 & 12 & 16 \\
\hline$>3.000 .000$ & 0 & 4 & 7 & 11 \\
\hline \multicolumn{5}{|l|}{ f. Jenis Pembayaran } \\
\hline Umum & 2 & 13 & 19 & 34 \\
\hline BPJS-PBI & 0 & 2 & 9 & 11 \\
\hline BPJS Non-PBI & 2 & 7 & 30 & 39 \\
\hline \multicolumn{5}{|c|}{ g. Frekuensi Kunjungan } \\
\hline Pertama Kali & 4 & 16 & 21 & 41 \\
\hline Setiap Minggu & 0 & 2 & 15 & 17 \\
\hline Setiap Bulan & 0 & 2 & 13 & 15 \\
\hline Lebih dari sebulan & 0 & 2 & 9 & 11 \\
\hline
\end{tabular}

Berdasarkan Tabel 2, dapat diketahui bahwa distribusi jenis kelamin terbanyak adalah perempuan sebanyak 54 orang dan sebagian besar responden perempuan merasa sangat puas yaitu sebanyak 35 orang $(64,8 \%)$. Distribusi usia terbanyak adalah usia 18-40 tahun dengan responden yang merasa sangat puas sebanyak 24 orang $(63,2 \%)$, sedangkan distribusi pendidikan terbanyak adalah pendidikan rendah dengan jumlah responden yang merasa sangat puas sebanyak 31 orang $(64,6 \%)$. Distribusi pekerjaan terbanyak adalah ibu rumah tangga sebanyak 24 orang dan distribusi penghasilan setiap bulan terbanyak adalah < 1.000.000 yaitu sebanyak 33 orang dimana sebagian besar responden merasa sangat puas . Jenis pembayaran yang paling banyak digunakan adalah BPJS Non-PBI sebanyak 39 orang dengan responden yang merasa sangat puas sebanyak 30 orang $(76,9 \%)$, sedangkan distribusi frekuensi kunjungan terbanyak adalah pertama kali yaitu sebanyak 41 orang.

Tabel 3. Distribusi Frekuensi Responden berdasarkan Minat Berobat Kembali

\begin{tabular}{lcc}
\hline Minat Berobat Kembali & $\mathrm{N}$ & $(\%)$ \\
\hline tidak berminat & 13 & 15,5 \\
berminat & 71 & 84,5 \\
\multicolumn{1}{c}{$\quad$ Total } & 84 & 100 \\
\hline
\end{tabular}

Berdasarkan Tabel 3, dapat diketahui bahwa mayorittas responden menyatakan berminat berobat kembali di RSD Kalisat, jika suatu saat mereka membutuhkan pengobatan, yaitu sebanyak 71 orang.

\section{Uji Normalitas}

Uji normalitas yang sesuai dengan penelitian ini adalah uji Kolmogorov Smirnov, dimana jika $p>0,05$ maka dataterdistribusi normal, sedangkan jika $p<0,05$ maka data tidak terdistribusi normal. Pada uji ini didapatkan nilai signifikansi $(p)=0,000$, maka data tidak terdistribusi normal.

\section{Uji Spearman's Rho}

Hasil uji korelasi Spearman dapat di lihat pada Tabel 4.

Tabel 4. Uji Spearman's Rho

\begin{tabular}{|c|c|c|c|}
\hline \multicolumn{2}{|c|}{ Spearman's Rho } & $\begin{array}{c}\text { Indeks } \\
\text { Kepuasan }\end{array}$ & $\begin{array}{l}\text { Minat Berobat } \\
\text { Kembali }\end{array}$ \\
\hline \multirow[t]{3}{*}{$\begin{array}{l}\text { Indeks } \\
\text { kepuasan }\end{array}$} & $\begin{array}{l}\text { Correlation } \\
\text { Coefficient }\end{array}$ & 1,000 & ,252 \\
\hline & $\begin{array}{l}\text { Sig. (2 } \\
\text { tailed) }\end{array}$ & . & 021, \\
\hline & $\mathrm{N}$ & 84 & 84 \\
\hline \multirow{3}{*}{$\begin{array}{l}\text { Minat } \\
\text { Berobat } \\
\text { Kembali }\end{array}$} & $\begin{array}{l}\text { Correlation } \\
\text { Coefficient }\end{array}$ & 252, & 1,000 \\
\hline & $\begin{array}{l}\text { Sig. }(2 \\
\text { tailed }\end{array}$ & ,021 & \\
\hline & $\mathrm{N}$ & 84 & 84 \\
\hline
\end{tabular}


Tabel 4 menunjukkan nilai signifikasi 0,021 yang menunjukkan bahwa korelasi antara indeks kepuasan tentang mutu pelayanan dimensi kehandalan dengan minat berobat kembali adalah bermakna. Nilai koefisien korelasi sebesar 0,252 menunjukkan bahwa arah korelasi positif dengan korelasi yang lemah. Hal ini berarti semakin tinggi indeks kepuasan tentang mutu pelayanan dimensi kehandalan maka semakin tinggi pula minat berobat kembali di Poli Rawat Jalan RSD Kalisat Kabupaten Jember.

\section{Pembahasan}

Berdasarkan hasil analisis data dalam penelitian ini indeks kepuasan pada pasien terbagi dalam netral, puas dan sangat puas terhadap pelayanan yang di berikan di poli rawat jalan RSD Kalisat Kabupaten Jember. Kepuasan yang dirasakan pasien dipengaruhi oleh banyak faktor. Tabel 2 menunjukkan bahwa sebagian besar pasien rawat jalan di RSD Kalisat Kab. Jember berjenis kelamin perempuan merasa sangat puas terhadap pelayanan yang diterimanya sebanyak 35 responden. Secara teori, jenis kelamin memiliki pengaruh pada pandangan jasa yang diberikan oleh suatu institusi pelayanan. Laki-laki cenderung sebagai pelindung dan pemberi rasa aman, sehingga dalam menilai suatu mutu pelayanan kesehatan ada kecenderungan untuk lebih menuntut atau mengkritik jika mereka merasa kurang puas [6]. Penggolongan usia dalam penelitian ini didasarkan pada teori hurlock yaitu responden yang berusia 18-40 tahun digolongkan dalam kategori dewasa dini, responden yang berusia 41-60 tahun termasuk kategori usia pertengahan dan responden yang berusia $>60$ tahun termasuk kategori usia lanjut. Berdasarkan Tabel 4.2 dapat diketahui bahwa sebagian besar responden termasuk kategori dewasa dini (usia 18-40 tahun) yaitu sebanyak 38 responden.

Kategori pendidikan terbanyak adalah responden yang termasuk dalam kategori pendidikan rendah yaitu sebanyak 48 responden merasa sangat puas terhadap pelayanan yang diterimanya, yaitu sebanyak 31 responden. Responden yang menyatakan mutu pelayanan baik dan tingkat kepuasan tinggi adalah responden yang memiliki pendidikan rendah. Responden yang memiliki pendidikan tinggi menyatakan mutu pelayanan dan tingkat kepuasan rendah. Hasil penelitian ini menunjukkan bahwa sebagian besar responden adalah ibu rumah tangga yaitu sebanyak 24 orang yang termasuk dalam kategori masyarakat yang tidak bekerja. Hal ini membuat responden memiliki pola pikir yang berbeda dalam memberikan penilaian berdasarkan apa yang dirasakan dengan informasi yang diperoleh. Ibu rumah tangga dalam penelitian ini cenderung merasa sangat puas dengan pelayanan yang diterimanya jika dibandingkan dengan profesi lain yaitu sebanyak 17 orang. Sebagian besar responden berpenghasilan < 1.000.000 merasa sangat puas terhadap pelayanan kesehatan yang diterimanya, yaitu sebanyak 20 orang. Pasien yang memiliki status ekonomi rendah pada umumnya memilki harapan dan tuntutan yang lebih rendah terhadap pelayanan medis. Mereka seringkali berharap penyakitnya segera sembuh apapun fasilitas yang diberikan. Dengan demikian mereka akan puas terhadap pelayanan yang diberikan secara standar umum masyarakat [7]

Mayoritas responden dalam penelitian ini menggunakan jenis pembayaran dengan BPJS Non-PBI sebanyak 39 orang. Sebagian besar responden baru pertama kali menggunakan jasa di RSD Kalisat Kabupaten Jember yaitu sebanyak 41 orang. dan merasa sangat puas terhadap pelayanan kesehatan yang diterimanya yaitu sebanyak 21 responden.

Dimensi kehandalan terbagi dalam 3 unsur, yaitu dependable, accurately, dan consistently [3]. Dependable berarti pelayanan diberikan secara akurat, dapat dipertanggungjawabkan dan dapat dipercaya. Unsur pertama yaitu dependable. It em pertanyaan dalam kuesioner yang sesuai dengan pengertian unsur dependable adalah penjelasan dokter tentang penyakit jelas. Penjelasan mengenai suatu penyakit diperlukan agar pasien mengerti dan bisa mengantisipasi perkembangan penyakitnya. Dala m memberikan penjelasan pada pasien, keterbukaan komunikasi menjadi sangat penting dalam proses konsultasi atau pengobatan sehingga informasi mengenai kesehatan dan pengobatan semakin jelas dan tingkat kesembuhan pasien juga semakin tinggi.

Unsur kedua yaitu accurately. Accurately berarti pelayanan yang diberikan tepat sesuai dengan anji yang ditawarkan. Item pertanyaan yang sesuai dengan pengertian accurately adalah kecepatan dokter dalam memeriksa pasien, kecepatan perawat dalam membantu permasalahan pasien, dan kecepatan bagian pendaftaran dan kasir dalam pelayanan. Sebagian besar responden menghabiskan waktu selama 6-10 menit ketika 
berkonsultasi atau menjalani pengobatan. Hal ini terjadi karena jumlah pasien yang relatif banyak sedangkan dokter yang melayani di setiap poli hanya 1 orang. Selain itu dokter yang melayani sering datang terlambat karena harus memberikan pengobatan pada pasien di rawat inap sehingga akan semakin mengurangi ketersediaan waktu melayani pasien. Pasien merasa puas dengan perhatian serta komunikasi yang membuat pasien merasa tenang sehingga dapat menarik minat pengguna layanan untuk memanfaatkan kembali suatu jasa[8].

Prosedur pelayanan menjadi sangat penting dalam memberikan kepuasan pada pasien. Prosedur pelayanan yaitu kemudahan tahapan pelayanan yang diberikan kepada masyarakat dilihat dari sisi kesederhanaan alur pelayanan [9]. Jika alur pelayanan sederhana, maka pasien akan lebih mudah mengerti alur pelayanan dan petugas pendaftaran lebih cepat dalam melakukan pelayanan sehingga tingkat kepuasan pasien lebih tinggi. Unsur ketiga yaitu consistenly. Consistently berarti secara terusmenerus pelayanan diberikan sesuai degan janji yang ditawarkan. Item pertanyaan yang sesuai dengan pengertian consistently adalah ketepatan pemeriksaan dimulai dan ketepatan pelayanan pendaftaran dimulai. Ketepatan pemeriksaan dimulai berarti bahwa dokter memulai pemeriksaan sesuai dengan jadwal yang tersedia atau waktu yang sesuai dengan yang dijanjikan pada pasien. Ketepatan pelayanan pendaftaran dimulai berkaitan dengan waktu buka loket pendaftaran yang sesuai dengan jadwal di rumah sakit. Kedua item pertanyaan tersebut sangat berhubungan dengan waktu tunggu yang dirasakan pasien. Menurut Chandra dalam Khairani,salah satu indikator kepuasan pasien adalah waktu tunggu, waktu tunggu yang lama terhadap pelayanan medis maupun nonmedis pada unit rawat jalan dan rawat inap akan mengurangi kepuasan pasien [10].

Berdasarkan Tabel 3 dapat diketahui bahwa terdapat hubungan yang bermakna antara indeks kepuasan pasien rawat jalan tentang mutu pelayanan dimensi kehandalan dengan minat berobat kembali di RSD Kalisat Kab. Jember dengan nilai significancy sebesar 0,021 . Hasil analisis statistik dengan menggunakan uji korelasi spearman's rho menunjukkan bahwa terdapat nilai koefisien korelasi sebesar 0,252 yang berarti bahwa terdapat hubungan yang lemah antara kedua variabel dalam penlitian ini.
Arah korelasi antara nilai significancy dengan koefisien korelasi dalam penelitian ini adalah positif. Pengertian positif dalam hal ini berarti, semakin tinggi indeks kepuasan yang dirasakan pasien tentang mutu pelayanan dimensi kehandalan maka minat untuk berobat kembali juga akan semakin tinggi. Hasil dari penelitian ini sesuai dengan penelitian Solikhah yang menyatakan ada hubungan positif bermakna antara kepuasan pasien dengan minat pemanfaatan ulang pelayanan pengobatan di Puskesmas, dilihat dari kepuasan pasien terhadap mutu pelayanan dimensi kehandalan di Poli Rawat Jalan RSD Kalisat Kab. Jember membuat pasien berminat untuk berobat kembali [11]. Trimurthy juga menyatakan bahwa persepsi pasien tentang kualitas pelayanan khususnya kehandalan pelayanan berhubungan dengan minat pemanfaatan ulang pelayanan rawat jalan puskesmas pandanaran Kota Semarang [12]. Hasil penelitian sesuai juga dengan penelitian Yalumini yang menyatakan bahwa terdapat hubungan antara kepuasan pasien dengan minat menggunakan jasa pelayanan keperawatan di RSUD Toto Kabila Kabupaten Bone Bolango [13]. Penelitian yang dilakukan oleh Suswardji dan Meliana juga membuktikan bahwa pasien yang puas dengan pelayanan yang diterima disebuah layanan kesehatan cenderung akan menggunakan layanan kesehatan itu kembali [14]. Hamidiyah juga menyebutkan bahwa ada hubungan antara persepsi pasien tentang kehandalan pelayanan dengan minat kunjungan ulang [15].

Setelah menggunakan pelayanan kesehatan,pasien akan mengalami level kepuasan atau ketidakpuasan. Kepuasan dan ketidakpuasan terhadap pelayanan kesehatan akan mempengaruhi perilaku pasien selanjutnya. Jika pasien puas, ia akan menunjukkan kemungkinan yang lebih tinggi untuk berobat kembali. Dimensi kehandalan merupakan satu dari lima dimensi mutu pelayanan yang digunakan dalam mengevaluasi mutu suatu jasa. Setiap pasien memiliki alasan atau kepuasan yang berbeda dalam memutuskan untuk memilih memanfaatkan kembali atau tidak suatu pelayanan kesehatan apabila suatu saat membutuhkan pelayanan kesehatan tersebut [16]. Jarak merupakan salah satu alasan pasien untuk memanfaatkan kembali jasa di RSD Kalisat Kab. Jember saat membutuhkan pelayanan kesehatan. Jarak yang lebih dekat 
dari rumah sehingga menghemat waktu dan biaya pasien lebih memilih RSD Kalisat Kab Jember dalam memanfaatkan pelayanan kesehatan. Penelitian yang dilakukan Halimatusa'diah juga mengungkapkan bahwa jarak yang dekat dari rumah pasien membuat pasien lebih memilih Puskesmas Ciputra Timur dalam mendapatkan pelayanan [17]. Akses yang mudah dijangkau juga menjadi alasan pasien untuk menggunakan kembali pelayanan kesehatan d RSD Kalisat Kab. Jember. Lokasi RSD Kalisat yang dibatasi oleh 10 kecamatan, yaitu Kecamatan Kalisat, Arjasa, Mayang, Silo, Ledokombo, Sumberjambe, Sukowono, Mumbulsari, Jelbuk, dan Pakusari membuat lebih banyak pasien yang berobat di RSD Kalisat Kab. Jember berasal dari daerah tersebut. Lokasi rumah sakit sangat strategis karena dapat dijangkau oleh transportasi umum dan berada di tengah-tengah masyarakat. Utama menjelaskan bahwa lokasi rumah sakit yang strategis seringkali menjadi alasan bagi pasien memilih pelayanan rumah sakit karena jarak rumah sakit dekat dengan tempat tinggalnya [18].

\section{Simpulan dan Saran}

Terdapat hubungan yang bermakna antara indeks kepuasan pasien tentang mutu pelayanan dimensi kehandalan dengan minat berobat kembali di RSD Kalisat Kabupaten Jember dengan korelasi yang lemah.

Saran untuk pihak RSD Kalisat Kabupaten Jember adalah melakukan suatu upaya monitoring dan evaluasi berkala terhadap kepuasan yang dirasakan pasien terkait kinerja tenaga medis dan pelayanan yang diterimanya. Pihak rumah sakit perlu menyediakan kotak saran atau media lain agar pasien bisa menilai pelayanan yang diberikan oleh rumah sakit.

\section{Daftar Pustaka}

[1] Indonesia. Profil Kesehatan Provinsi Jawa Timur Tahun 2015. Dinas Kesehatan Provinsi Jawa Timur; 2015.

[2] Khasanah I, Pertiwi OD. Analisis Pengaruh Kualitas Pelayanan terhadap Kepuasan Konsumen RS St. Elisabeth Semarang [Internet]. 2010 Okt [cited 2016 Jan 29] ; 12(2). Available from http://www.jurnal.widyamanggala.ac.id/i ndex.php/asetwm/article/view/35/28
[3] Supriyanto S, Ernawaty. Pemasaran Industri Jasa Kesehatan. Yogyakarta: C.V Andi Offset; 2010.

[4] Nurlinda RA. Pengaruh Customer Satisfaction Strategy terhadap Peningkatan Kepuasan Pasien [Internet]. 2013 Mei [cited 2016 Jan 29]; 10 (2). Available from http://digilib.esaunggul.ac.id/pengaruhcustomer-satisfaction-strategyterhadap-peningkatan-kepuasan-konsumen2218.html

[5] Kotler P, Keller KL. Manajemen Pemasaran. Edisi 12. Jakarta: Indeks; 2009.

[6] Munaryo. Analisis Pengaruh Persepsi Mutu Pelayanan Rawat Inap terhadap Minat Pemanfaatan Ulang di RSUD Kab. Brebes Tahun 2008. Tesis. Semarang: Program Pascasarjana Universitas Diponegoro. 2008.

[7] Potter AP, Perry GA. Fundamentas of Nursing: Concepts, Process and Practice. St Louis: Mosby Year Book; 1997.

[8] Widartini NG, Nopiyani NM. Evaluasi Tingkat Kepuasan Masyarakat Pengguna Layanan Posyandu di Wilayah Kerja Puskesmas I Denpasar Selatan Tahun 2013 [Internet]. 2013 Jul [cited 2016 Jan 26 ]; 1(3). Available from http://ojs.unud.ac.id/index.php/jch/article/vie w/7653/5744

[9] Mote,F. Analisis Indeks Kepuasan Masyarakat (IKM) terhadap Pelayanan Publik di Puskesmas Ngesrep Semarang. Tesis. Semarang: Program Pascasarjana Universitas Diponegoro. 2008.

[10] Khairani L, Manjas M, Fendy R. Faktorfaktor yang Mempengaruhi Kepuasan Pasien Rawat Jalan RSUD Pasaman Barat. Tesis. Padang: Universitas Andalas. 2011.

[11] Solikhah. Hubungan Kepuasan Pasien dengan Minat Pasien dalam Pemanfaatan Ulang Pelayanan Pengobatan. Jurnal Manajemen Pelayanan Kesehatan. 2008; 11.

[12] Trimurthy, I. Analisis Hubungan Persepsi Pasien tentang Mutu Pelayanan dengan Minat Pemanfaatan Ulang Pelayanan awat Jalan Puskesmas Pangandaran Kota Semarang. Tesis. Semarang: Program 
Pascasarjana Universitas Diponegoro. 2008.

[13] Yalumini N, Zees RF, Aswad A. Hubungan Kepuasan Pasien dengan Minat Menggunakan Jasa Pelayanan Keperawatan di RSUD Toto Kabila Kabupaten Bone Bolango [Internet]. 2015 Jan [cited 2016 Jan 26]. Available from http://kim.ung.ac.id/index.php/KIMFIKK/artic le/download/10817/10695

[14] Suswardji EM, Meliana, M. Pengaruh Pelayanan Puskesmas terhadap Kepuasan Pasien di Puskesmas Adiarsa Karawang Timur. Jurnal Manajemen. 2012; 9.

[15] Hamidiyah A. Hubungan Persepsi Pasien tentang Kualitas Pelayanan dengan Minat Kujungan Ulang di Klinik Umum Rumah
Sakit Bhineka Bakti Husada Kota Tangerang Selatan. Skripsi. Jakarta: Fakultas Kedokteran dan Ilmu Kesehatan Universitas Islam Negeri Syarif Hidayatullah. 2013.

[16] Muninjaya GAA. Manajemen Mutu Pelayanan Kesehatan. Jakarta: EGC; 2011

[17] Halimatusa'diah. Hubungan Perepsi Pasien terhadap Mutu Pelayanan dengan Minat Pemanfaatan Ulang Rawat Jalan Umum di Puskesmas Ciputra Timur Tahun 2015. Skripsi. Jakarta: Fakultas Kedokteran dan IImu Kesehatan UIN Syarif Hidayatullah. 2015.

[18] Utama S. Memahami Fenomena Kepuasan Pasien Rumah Sakit. Jurnal Manajemen Pelayanan Kesehatan. 2005; 9(1): 1-8. 